\title{
CRYSTALLIZATION OF a AND $Y$ PHASES IN ISOTACTIC POLYPROPYLENE WITH LOW ETHYLENE CONTENT: ISOTHERMAL CRYSTALLIZATION AND SECONDARY CRYSTALLIZATION
}

Koji Nozaki $^{1 *}$, Yasuaki Endo ${ }^{1}$, Takashi Yamamoto ${ }^{1}$ and Masahiro Naiki ${ }^{2}$

1. Department of Physics, Faculty of Science, Yamaguchi University, Yamaguchi 753-8512, Japan.

2. Ube Research Laboratory, Ube Industries, Ltd, Nishihon-machi, Ube 755-8633, Japan.

*Correspondence Author: nozaki@sci.yamaguchi-u.ac.jp

\section{ABSTRACT}

Crystallization and melting behaviors of isotactic polypropylene (IPP) with low ethylene content during an isothermal process and on heating just after it are investigated by means of in-situ x-ray diffraction. At every isothermal temperature investigated here, the formations of both $\alpha$ and $Y$ phases are confirmed. The ratio of $Y$ to $\alpha$ increases with an increase in isothermal temperature. On heating just after the isothermal process, the $Y$ starts melting at lower temperature than the $a$. This may be due to the small crystallite size of the $\mathrm{Y}$ crystallization during the isothermal process. On cooling after the completion of the isothermal crystallization, the secondary crystallization accelerates, and the $\mathrm{Y}$ phase crystallizes predominantly. The fractionation is considered to occur in the primary crystallization during the isothermal process. The low molecular weight portion of the materials, which remained in amorphous regions of the spherulite during the isothermal process, crystallizes into the $\mathrm{Y}$ phase in the secondary crystallization. Furthermore, the fractionation behavior seems to be enhanced at higher temperature.

\section{INTRODUCTION}

Isotactic polypropylene (IPP) is one of the most fundamental polymers, as well as polyethylene, and has been widely investigated from academic and industrial interests since Natta et al. first succeeded to synthesize it in 1955 (1). Although the 
chemical structure of IPP is simple, it shows complex crystal structures, in all of which the molecule takes a $3_{1}$ helix conformation. In IPP, the $3_{1}$ helix molecule can takes one of the four possible states which are different in helix-hand (right or left) and in orientation of the methyl side group bond relative to the helix axis (up or down). Thus, the existence of the four states of the molecular structure results in various rules of the molecular packing in the crystalline phases and causes the complex polymorphous behavior. IPP shows three different crystalline phases, $\alpha$ (2), $\beta$ (3) and $Y(4,5)$ phases, the appearance of which depends on crystallization condition and on material grade.

To control the crystallization behavior and the polymorph of polymer materials is of great importance for applications, since they strongly affect the properties of the materials. For example, the morphology of the polymer material changes depending on which polymorph crystallizes predominantly, and directly influences the optical transparency and mechanical properties.

The a phase of IPP is the most prevalent crystalline phase. It forms upon cooling of the melt and from solution. Two a phases, a 1 and $\mathbf{a} 2$, have been found (6-9). The meta-stable a 1 phase generates on quenching from the melt, while, the stable a 2 crystallizes during an isothermal process at high temperature. The a 2 can be also obtained by annealing of the a 1 phase at high temperature. In our previous work (10), it was confirmed that the reordering from a 1 to a 2 at high temperature proceeds by the melting of the a 1 crystals and successive recrystallization of the $a 2$.

The $\mathrm{Y}$ phase was first reported during the 1960s. A large amount of it is obtained by crystallization under high pressure $(11,12)$, by using low molecular weight materials $(13,14)$ and by co-polymerization with low content ethylene $(13,15-18)$. The 
crystal structure of the $\mathrm{Y}$ phase had long remained a puzzle. The breakthrough in understanding of the $\mathrm{Y}$ structure dated from a work by Brückner and Meille (19). According to it, the $Y$ phase shows a unique structure, which is different from common polymer crystals where the molecules are parallel to each other. The $\mathrm{Y}$ phase is made up of a succession of bilayers composed of parallel chains, and the chain axes in the adjacent bilayers tilt at an angle of $80^{\circ}$.

It was found that the presence of ethylene comonomer enhanced the formation of the $\mathrm{Y}$ phase (4). When IPP copolymer with low ethylene content is used, with increasing in ethylene content and in crystallization temperature, the $\mathrm{Y}$ crystals in the sample increase (18). When IPP crystallizes under high pressure, pure $Y$ phase material can be obtained. Mezghani and Philips determined the equilibrium melting point data and made a temperature-pressure phase diagram for the $\alpha$ and $Y$ phases (20). They suggested that the equilibrium melting point of the $Y$ phase may be slightly higher than that of the a phase at atmospheric pressure, and that the a phase is the most stable phase at low temperature; the $a$ to $Y$ transition exists below the melting point. Furthermore, in the case of IPP copolymer with low ethylene content, the temperature range, where the $\mathrm{Y}$ phase is more stable, is extended to a low temperature region (18).

Lotz et al. found that either the $\mathrm{a}$ or $\mathrm{Y}$ crystal can easily grow epitaxially onto lamellae of the other phase (21-23). On the contact surface, which corresponds to the ac-plane for the a crystal, if the opposite hand helix attaches, the a crystal remains. On the other hand, if the same hand helix attaches, branched lamellae of the a crystal or the pure $\mathrm{Y}$ crystal grows; the $\mathrm{Y}$ crystal can grow without the primary nucleation. 
In crystallization of polymer materials, a secondary crystallization is often observed (24-25). The first step of the crystallization process, the growth of the spherulites until impinging on each other seems to be called primary crystallization. On the other hand, secondary crystallization process can be observed when the material is completely composed of spherulites, and an increase in crystallinity can only occur within the spherulites. Recently, Kolb et al. concluded from their in-situ microbeam $\mathrm{x}$-ray experiment on IPP that the secondary crystallization occurrs during the growth of the spherulites and is strongest behind the growth front of the spherulites, that is, the conventional experiment may observe both the primary and the secondary crystallization processes at the same time.

In this work, the isothermal crystallization process of IPP copolymer with low ethylene content is investigated by means of time-resolved x-ray diffraction. The relative amount of the $\mathrm{Y}$ phase is compared at various isothermal temperatures. The secondary crystallization, after the completion of the isothermal crystallization, is also observed. Furthermore, self-seeding crystallization is performed after the partial melting of the sample in order to investigate crystallization at high temperature.

\section{EXPERIMENTAL}

The IPP copolymer used here was kindly supplied by Grand Polymer, Ltd. The weight-averaged molecular weight $\left(\mathrm{M}_{\mathrm{w}}\right)$ and the molecular weight distribution $\left(\mathrm{M}_{\mathrm{w}} / \mathrm{M}_{\mathrm{n}}\right.$ : $M_{n}$ is number-averaged molecular weight) determined by GPC were 267,000 and 4.1, respectively. The ethylene content was $3.3 \mathrm{wt} \%$. The sample for x-ray diffraction was first melted at $200^{\circ} \mathrm{C}$, and then quenched to room temperature.

X-ray diffraction (XRD) was carried out by using a diffractometer with a 
imaging plate system (Mac Science; DIP220). Graphite-monochromatized CuKa $\mathrm{X}$-rays $(40 \mathrm{kV}, 250 \mathrm{~mA})$ were transmitted through the sample, the temperature of which was controlled within $\pm 0.1^{\circ} \mathrm{C}$ by a PID controller. Some XRD measurements were also performed by using a convenient diffractometer (Rigaku; RAD-IIA).

The typical temperature control sequence in a series of XRD is shown in Fig.1. The sample was first heated to and held at $200^{\circ} \mathrm{C}$ for $10 \mathrm{~min}$ in order to melt the material completely (a in Fig. 1). After cooling to an isothermal crystallization temperature $\left(T_{\mathrm{c}}\right)$ at the rate of $10^{\circ} \mathrm{C} / \mathrm{min}$ (b in Fig. 1), the time-resolved XRD patterns were collected during the isothermal crystallization (c in Fig. 1). After the completion of the isothermal crystallization, the sample was heated again; the melting behavior of the material crystallized during the isothermal crystallization was investigated (d in Fig. 1). Another pattern was that after the completion of the isothermal crystallization, the sample was cooled to room temperature at the rate of $10^{\circ} \mathrm{C} / \mathrm{min}$; the result of the secondary crystallization was observed (e in Fig. 1).

After quenching of the melted material (f and $g$ in Fig. 1), the sample was heated again to a temperature below the melting temperature (h and i in Fig. 1), where all of the regions of the crystal had not been melted (partial melting state). When the sample was cooled to room temperature again ( $j$ in Fi.g 1), the self-seeding crystallization might occur because the remaining crystallites served as nuclei in the material.

\section{RESULTS AND DISCUSSION}

Figure 2 shows the time-resolved XRD patterns during the isothermal crystallization at $T_{\mathrm{c}}=117^{\circ} \mathrm{C}$. The reflections around $2 \theta=18.3^{\circ}$ and $19.8^{\circ}$ correspond to 
130 of the a phase and 117 of the $Y$ phase, respectively. Other peaks between $2 \theta$ $=14-22^{\circ}$ are superimposed ones of the reflections of the two phases. Since only the a 130 and the $Y 117$ are discrete reflections, the ratio of the intensities of the two peaks is taken as the ratio of the two phases. Of course, the correct ratio should be estimated by using the structure factors, however, that of the $\mathrm{Y}$ phase has not been described. At the isothermal crystallization temperature of $T_{\mathrm{c}}=117^{\circ} \mathrm{C}$, both phases formed from the early stage of the crystallization. This result is consistent with the result in previous work (27). The peak intensities of the a 130 and $Y 117$ reach to almost constant values at 100 min; i. e. the primary isothermal crystallization completes in $100 \mathrm{~min}$.

Figure 3 shows the XRD patterns on heating just after the completion of the isothermal crystallization at $117^{\circ} \mathrm{C}$. The $\mathrm{Y} 117$ peak obviously begins to decrease earlier than the a 130 peak; the crystallites of the $\mathrm{Y}$ phase melts at a lower temperature. This tendency was confirmed for all isothermal crystallization temperatures investigated in this experiment. The lamellar thickness of the $Y$ phase which generates during the isothermal process is considered to be thinner than that of the a phase. The melting behavior of the IPP material containing the $a$ and $Y$ crystals was investigated by XRD also in the previous work (27). Although the material used in the previous work was isothermally crystallized, the sample was first cooled to room temperature and then heated again. The annealing effect could not be negligible. In this work, on the other hand, the sample was heated just after the isothermal process. Therefore, the crystallites in the material are those that grew during the isothermal crystallization. The melting behavior of the crystal, which is generated only during the isothermal crystallization, can be investigated. When the material which contains both the $\alpha$ and the $Y$ crystals are used, two melting peaks are sometimes observed by differential scanning calorimetry (DSC) (18). From the present result of the XRD, the lower peak in DSC may be identified as the melting of the $\mathrm{Y}$ crystal. 
The ratios of the $\mathrm{Y}$ to the $\mathrm{a}$ phases crystallized isothermally at various temperature are shown in Fig. 4. The amount of the $Y$ phase increases with an increase in isothermal crystallization temperature. In previous work $(16-18,20)$, it was found that more material crystallizes into the $Y$ phase at a lower cooling rate. These two results are closely consistent with each other. According to Mezghani and Phillips (20), the equilibrium melting temperature of the $\mathrm{Y}$ phase is slightly higher than that of the a phase in the case of IPP homopolymer. The $Y$ phase is expected to be more stable at high temperature. Furthermore, Foresta et al. (18) suggested that there is a region in which the $Y$ phase has a lower free energy than the a phase, and this region extends to lower temperatures with increasing comonomer content. Hence, the result that the $\mathrm{Y}$ phase is preferred at higher isothermal crystallization temperature can be easily expected from the thermodynamic consideration. However, for kinetic reasons, the formation of the $\mathrm{Y}$ phase may have some relationship with a fractionation during crystallization or a secondary crystallization mentioned below. It should be noticed that, the $\mathrm{Y} / \mathrm{a}$ ratio shows a significant jump around $115^{\circ} \mathrm{C}$. The origin of this phenomenon cannot be understood based on present work.

Figure 5 shows the x-ray diffraction pattern at the final stage of the isothermal crystallization at $130^{\circ} \mathrm{C}$ (a) and that after cooling from the isothermal temperature to room temperature (b), respectively. At the final stage of the isothermal crystallization, the change in the x-ray diffraction pattern had already stopped. The pattern in Fig.5 (a) is composed of the Bragg reflections of the $\mathrm{a}$ and the $\mathrm{Y}$ phase and the halo scattering arising from the amorphous region. After cooling, the halo scattering intensity $\left(2 \theta=10-25^{\circ}\right)$ decreases, and the Bragg intensities increase instead. This behavior is expected to be caused by the secondary crystallization, which accelerates during the cooling after the completion of the isothermal primary crystallization. It should be 
noticed that all the Bragg peak intensities which belong to the $\mathrm{Y}$ phase increase. Only the peak intensity of the a 130 did not change. That is, the $\mathrm{Y}$ phase forms predominantly in the secondary crystallization.

When IPP copolymer with low ethylene content is quenched from the melt, the dominant phase crystallized is the a phase, while, when it is quenched from the final stage of the isothermal crystallization, the preferred crystalline phase is the $\mathrm{Y}$ phase. The latter case is considered to be due to a fractionation during crystallization of the polymer. The material used here has a significant molecular weight distribution $\left(\mathrm{M}_{\mathrm{w}} / \mathrm{M}_{\mathrm{n}}=4.1\right)$. During the primary crystallization in the isothermal process, the molecules with high molecular weight mainly crystallize, while the low molecular weight molecules still remain in the amorphous region due to their slow crystallization rate. In the secondary crystallization, the remaining low molecular weight portion crystallizes. For low molecular weight, the molecules tend to crystallize into the $Y$ phase rather than the a phase by nature $(13,14)$. Especially, in the case of ethylene copolymer, the ethylene monomer may accumulate in the low-molecular weight portion. Therefore, the secondary crystallization increases the fraction of the $Y$ phase.

According to Kolb et al. (26), the secondary crystallization occurs within the spherulitic microstructure. Furthermore, they confirmed by microbeam XRD that the secondary crystallization was occurring during the growth of the spherulites, i. e. the primary and secondary crystallizations seem to proceed in different regions in the growing spherulite at the same time. From this point, the formation of the $Y$ phase during the isothermal crystallization may be a result of the secondary crystallization of the low molecular weight fraction. At a high isothermal temperature, the slower growth rate of the crystal assists the fractionation; the $\mathrm{Y}$ crystals crystallized in the secondary crystallization may increase. Further investigation is be necessary toclarify the situation. 
Figures 6 (a) and (b) show the x-ray diffraction pattern of the material prepared by quenching to room temperature from the melt and by cooling from the partial melting state, where the crystallites (a ) still remains at a temperature just below the melting point ( $\mathrm{i}$ in Fig. 1). It should be noticed that the a phase crystallizes during quenching from the melt (Fig.6 (a)), while in the case of cooling from the partial melting state, some amount of the $\mathrm{Y}$ phase appear (Fig. 6 (b)). In this case, primary nucleation is not necessary for crystallization, because the crystallites already existed in the material due to incompletion of the melting. The crystallization temperature is relatively higher than that in the case of cooling from the complete melt. In such a high temperature situation, only the high molecular weight portion is considered to crystallize predominantly, and the low molecular weight one cannot crystallize at such a high temperature even in the secondary crystallization process. Thus, the fractionation may be enhanced. As a result, the $Y$ phase is expected to increase by cooling from the partial melting state. In this case, most of the $Y$ crystals form in the lower temperature region during the cooling process.

\section{CONCLUSIONS}

The crystallization behaviors of the IPP with low ethylene content were investigated by using XRD. In the isothermal crystallization, formation of the $a$ and $\mathrm{Y}$ crystals were observed. When the IPP material was heated to the melting temperature just after completion of the isothermal crystallization, the $\mathrm{Y}$ phase started melting at lower temperature. The $\mathrm{Y}$ crystal is suggested to be smaller than the a one. When the sample was cooled from the final stage of the isothermal crystallization, the $\mathrm{Y}$ phase increased during the cooling, where only the secondary crystallization was expected to proceed. The $\mathrm{Y}$ crystal forms predominantly in the secondary 
crystallization. This is due to the fractionation during the isothermal crystallization. The low molecular weight portion remains in the amorphous region in the spherulite in the primary crystallization, and they are suggested to crystallize into the $Y$ phase by the secondary crystallization process. In the case of the cooling from the partial melting state, it was found that the fractionated crystallization is enhanced; the $\mathrm{Y}$ phase increases, although the dominant phase is a when the sample is cooled from the complete melt.

\section{ACKNOWLEDGEMENTS}

This work was supported by a Grant-in-Aid for Scientific Research on Priority Areas, "Mechanism of Polymer Crystallization (No. 12127206) and by a Grant-in-Aid for Scientific Research (No. 14540378) from the Ministry of Education, Culture, Sports, Science and Technology. 


\section{REFERENCES}

1. Natta, G.; Pino, P.; Coradini, P. Crystalline High Polymers of a -Olefins. J. Am. Chem. Soc. 1955, 77, 1708-1710.

2. Natta, G.; Corradini, P. Structure and Properties of Isotactic Polypropylene. Nuovo Cimento Suppl. 1960, 15, 40-51.

3. Keith, H. D.; Padden, F. J. Jr.; Walfer, H. M.; Wickoff, H. W. Evidence for a Second Crystal Form of Polypropylene. J. Appl. Phys. 1959, 30, 1485-1488.

4. Turner-Jones, A.; Aizlewood, J. M.; Beckett, D. R. Crystalline forms of Isotactic Polypropylene. Makromo. Chem. 1964, 74, 134-158.

5. Kardos, J. L.; Christiansen, J. L.; Baer, E. Structure of Pressure-Crystallized Polypropylene. J. Polym. Sci. 1966, 4, 777-778.

6. Hikosaka, M.; Seto, T. Order of the Molecular Chains in Isotactic Polypropylene Crystals. Polymer J. 1973, 3, 111.-127.

7. De Rosa, C.; Guerra, G.; Napolitano, R.; Petraccone, V.; Pirozzi, B. Conditions for the a 1-a 2 Transition in Isotactic Polypropylene samples. Eur. Polym. J. 1984, 20, 973-941.

8. Guerra, G.; Petraccone, .; Corradini, P.; Rosa, C. De; Napolitano, R.; Pirozzi, B.; Giunchi, G. Crystalline Order and Melting Bhavoir of Isotactic Polypropylene (a -form). J. Polym. Sci. Polym. Phys. 1984, 22, 1029-1039.

9. Corradini, P.; Giunchi, G.; Petraccone, V.; Pirozzi, B.; Vidal, H. M. Structural Variations in Crystalline Isotactic Polypropylene (a form) as a Function of Thermal Treatments. Gazzetta Chim. Ital. 1980, 110, 413-418.

10. Naiki, M.; Kikkawa, T.; Endo, Y.; Nozaki, K.; Yamamoto, T.; Hara, T. Crystal Ordering of a Phase Isotactic Polypropylene. Polymer 2000, 42, 5471-5477.

11. Campbell, R. A.; Phillips, P. J.; Lin, J. S. The Gamma Phase of High-Molecular-Weight Polypropylene: 1. Morphological Aspects. Polymer 1993, 34, $4809-4816$. 
12. Pae, K. D.; Morrow, D. R.; Sauer, J. A. Interior Morphology of Bulk Polypropylene. Nature 1966, 211, 514-515.

13. Morrow, D. R.; Newman, B. A. Crystallization of Low-Molecular-Weight Polypropylene Fractions. J. Appl. Phys. 1968, 39(11), 4944-4950.

14. Addink, E. J.; Beintema, J. Polymorphism of Crystalline Polypropylene. Polymer 1961, 2, 185-193.

15. Zimmermann, H. J. Structural Analysis of Random Propylene-Ethylene Copolymers. J. Macromol. Sci. Phys. 1993, B32(2), 141-161.

16. Mazghani, K.; Phillips, J. Y -Phase in Propylene Copolymers at Atmospheric Pressure. Polymer 1995, 36(12), 2407-2411.

17. Laihonen, S.; Gedde, U. W.; Werner, P. E.; Martinez-Salazar, Crystallization Kinetics and Morphology of Poly(propylene-stat-ethylene) Fractions. J. Polymer 1997, 38, 361-369.

18. Foresta, T.; Piccarolo, S.; Goldbeck-Wood, G.; Competition between $a$ and $Y$ phases in Isotactic Polypropylene: Effect of Ethylene Content and Nucleating Agents at Different Cooling Rates. Polymer 2001, 42, 1167-1176.

19. Bruckner, S.; Meille, S. V. Non-Parallel Chains in Crystalline Y -Isotactic Polypropylene. Nature 1989, 340 455-457.

20. Mezghani, K.; Phillips, P. J. The Y -Phase of High Molecular Weight Isotactic Polypropylene: III. The Equilibrium Melting Point and the Phase Diagram. Polymer 1998, 39(16), 3735-3744.

21. Lotz, B.; Graff, S.; Wittmann, J. C. Crystal Morphology of the Y (Triclinic) Phase of Isotactic Polypropylene and its Relation to the a Phase. J. Polym. Sci. Polym. Phys. 1986, 24, 2017-2032.

22. Lotz, B.; Graff, S.; Straupé C.; Wittmann, J. C. Single Crystals of Y Phase Isotactic Polypropylene: Combined Diffraction and Morphological Support for a Structure with Non-Parallel Chains. Polymer 1991, 32(16), 2902-2910. 
23. Lotz, B.; Wittmann, J. C.; Lovinger, A. J. Structure and Morphology of Poly(propylenes): a Molecular Analysis. Polymer 1996, 37(22), 4979-4992.

24. Zachmann, H. G.; Stuart, H. A. Main- and After-Crystallization of Terylene from Glass State. Makromol. Chem. 1960, 41, 131-147.

25. Schultz, J. M.; Fischer, E. W.; Schaumburg, O.; Zachmann, H. G. Small-Angle x-ray scattering Studies of Melting. J. Polym. Sci. Polym. Phys. 1980, 18, 239-245.

26. Kolb, R.; Wutz, C.; Stribeck, N.; Krosigk, G. V.; Riekel, C. Investigation of Secondary Crystallization of Polymers by means of Microbeam X-ray Scattering. Polymer 2001, 42, 5257-5266.

27. Alamo, R. G.; Kim, M. H.; Galante, M. J.; Isasi, J. R.; Mandelkern, L. Structural and Kinetic Factors Govering the Formation of the $\mathrm{Y}$ Polymorph of Isotactic Polypropylene. Macromolecules 1999, 32, 4050-4064. 


\section{FIGURE CAPTIONS}

\section{FIGURE 1}

Typical sequence of the temperature control in a series of XRD. The sample was first heated to and held at $200^{\circ} \mathrm{C}$ for $10 \mathrm{~min}$ (a). After cooling an isothermal temperature $\left(T_{\mathrm{c}}\right)$ at the rate of $10^{\circ} \mathrm{C} / \mathrm{min}(\mathrm{b})$, the time-resolved $\mathrm{XRD}$ patterns are

collected during the isothermal process (c). After the completion of the isothermal crystallization, the sample was heated again; the melting behavior was observed (d). The sample was then cooled to room temperature at the rate of $10^{\circ} \mathrm{C} / \mathrm{min}$ after the completion of the isothermal crystallization; the result of a secondary crystallization was observed (e). The dotted line exhibits the sequence of the partial melting and crystallization process. After quenching of the melted sample (f, g) it was heated again to a temperature below the melting temperature (partial melting state, $\mathrm{h}$ and $\mathrm{i}$ ), and the sample was cooled to room temperature again $(\mathrm{j})$.

\section{FIGURE 2}

Time-resolved XRD patterns during the isothermal crystallization at $T_{\mathrm{c}}=117^{\circ} \mathrm{C}$. The reflections around $2 \theta=18.3^{\circ}$ and $19.8^{\circ}$ correspond to 130 of the $a$ and 117 of the $Y$ phase, respectively. The other peaks between $2 \theta=14-22^{\circ}$ are superimposed ones of the reflections of the two phases.

\section{FIGURE 3}

$\mathrm{XRD}$ patterns on heating just after the isothermal process at $117^{\circ} \mathrm{C}$. the $\mathrm{Y} 117$ peak begins to decrease earlier than the a 130.

FIGURE 4

Ratios of the $\mathrm{Y}$ to the $\mathrm{a}$ phases crystallized at various isothermal 
temperatures. Since only the a 130 and the Y 117 are discrete reflections, the ratio of the intensities of the two peaks was taken as the ratio of the two phases. The correct ratio should be estimated by using the structure factors, however, that of the $Y$ phase has not been described. The amount of the $Y$ phase increases with an increase in the isothermal temperature. It should be noticed that, the $Y / \alpha$ ratio shows a significant jump around $115^{\circ} \mathrm{C}$.

\section{FIGURE 5}

$\mathrm{XRD}$ pattern at the final stage of the isothermal crystallization at $130^{\circ} \mathrm{C} \quad$ (a), and after cooling to room temperature (b). The halo scattering arising from the amorphous region decreases and Bragg intensity of only the $Y$ phase increases after cooling.

\section{FIGURE 6}

XRD pattern of the material prepared by quenching from the melt (a) and that of the material prepared by cooling from the partial melting state (corresponding to the line h-j in Fig. 1) (b). In the former case, only the a phase usually is observed. After cooling from the partial melting state, the $Y$ phase increases. 


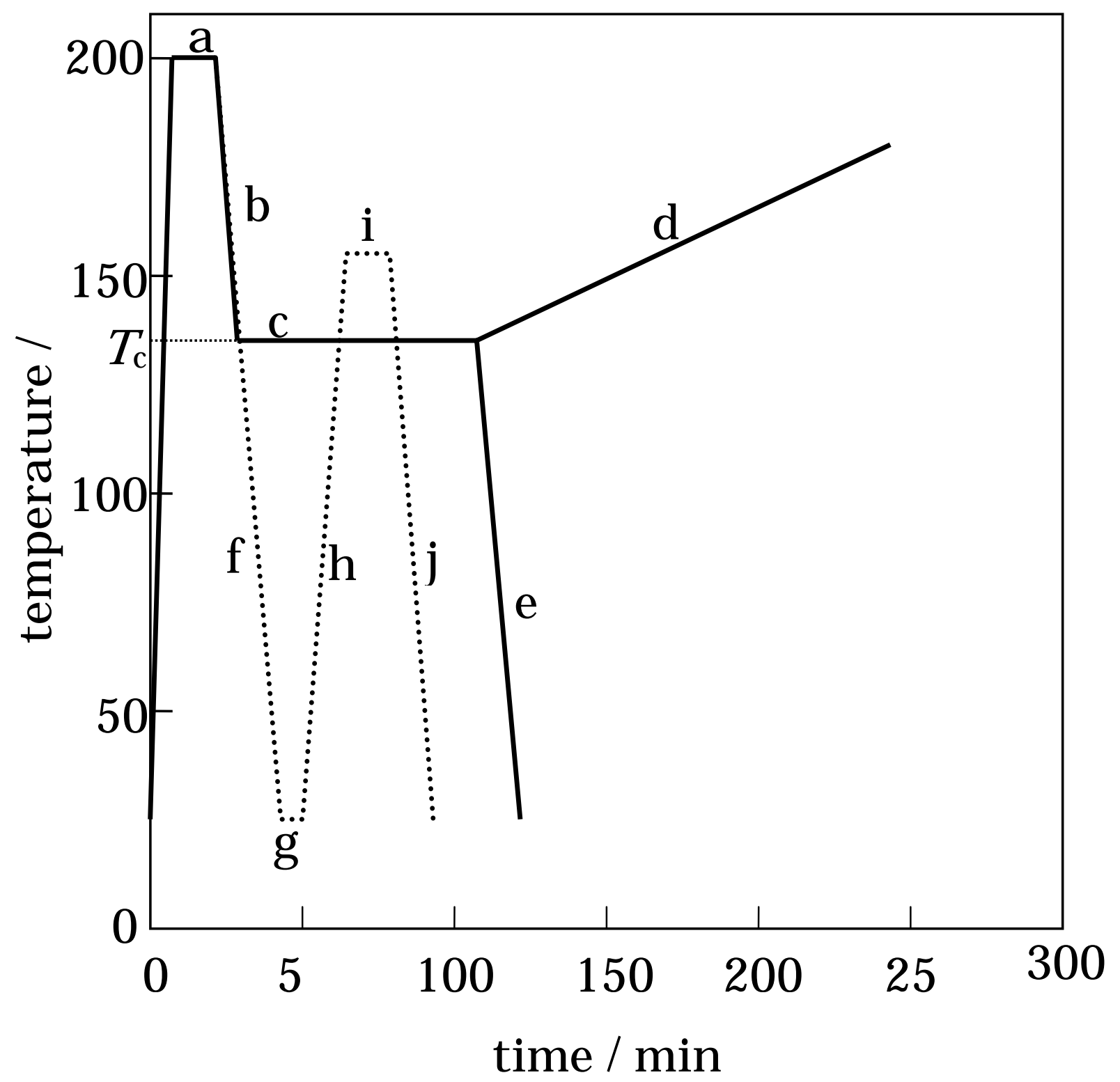

Figure 1 Koji Nozaki, et al. 


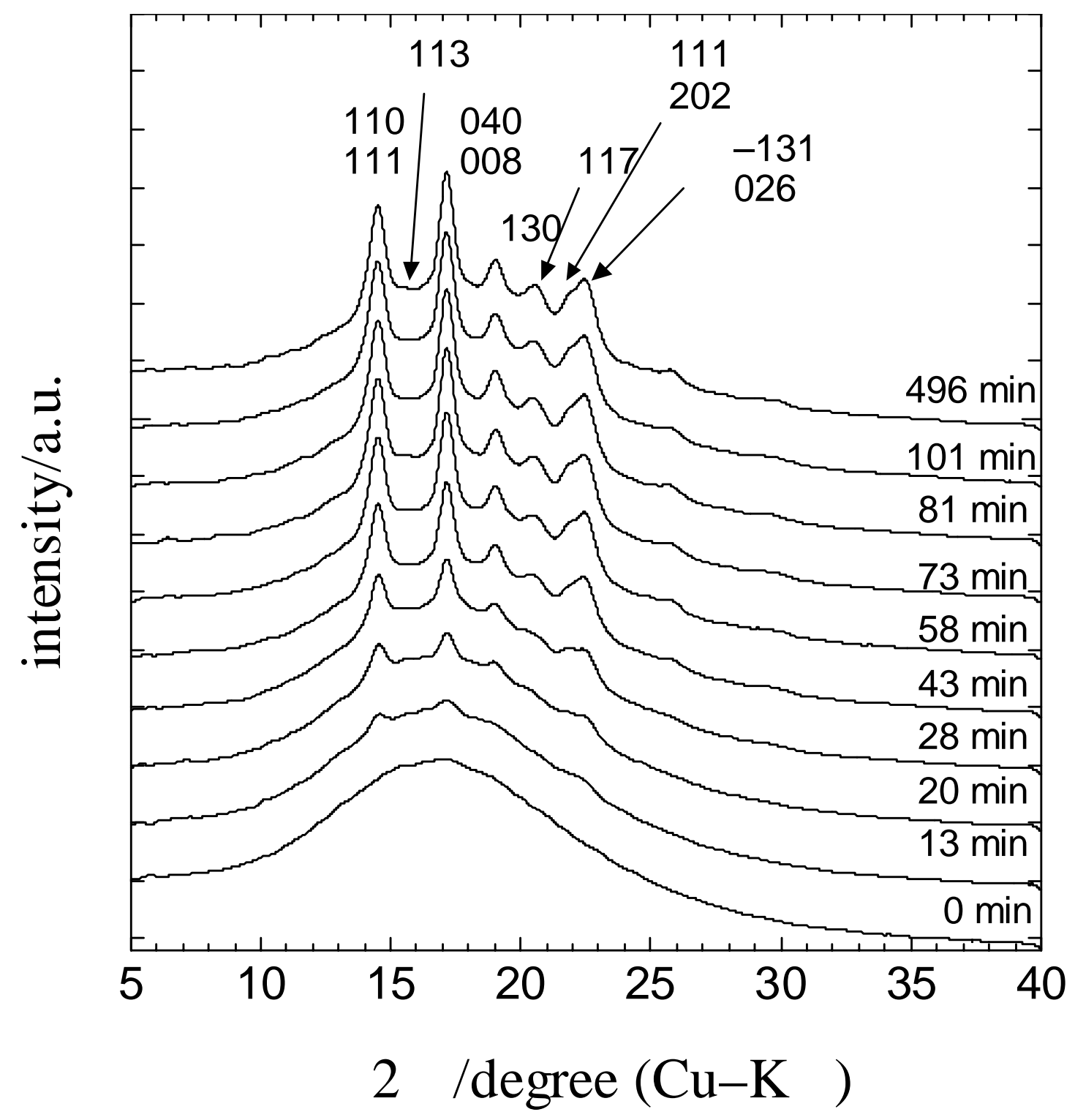

Figure 2 Koji Nozaki, et al. 


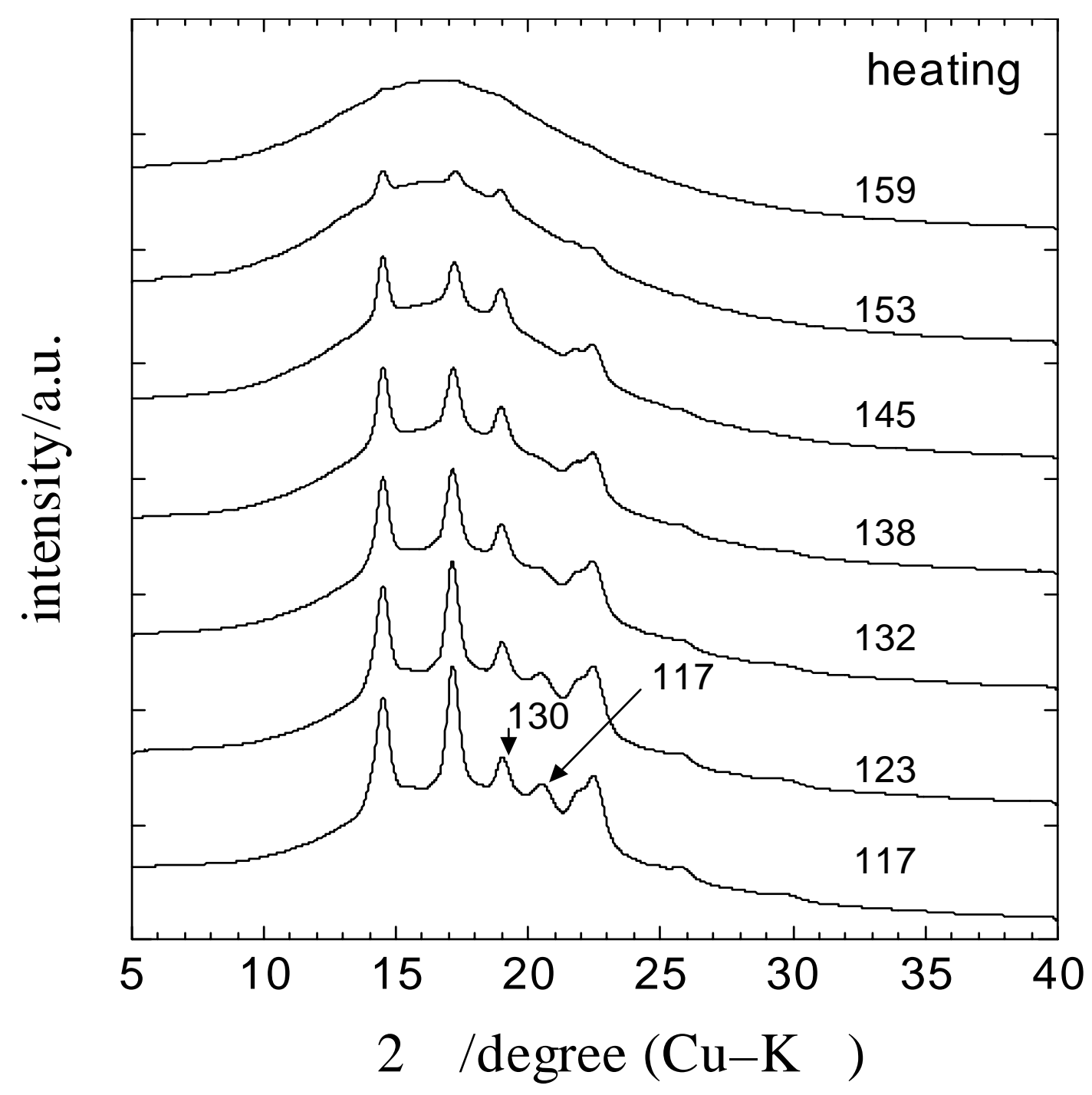

Figure 3 Koji Nozaki, et al. 


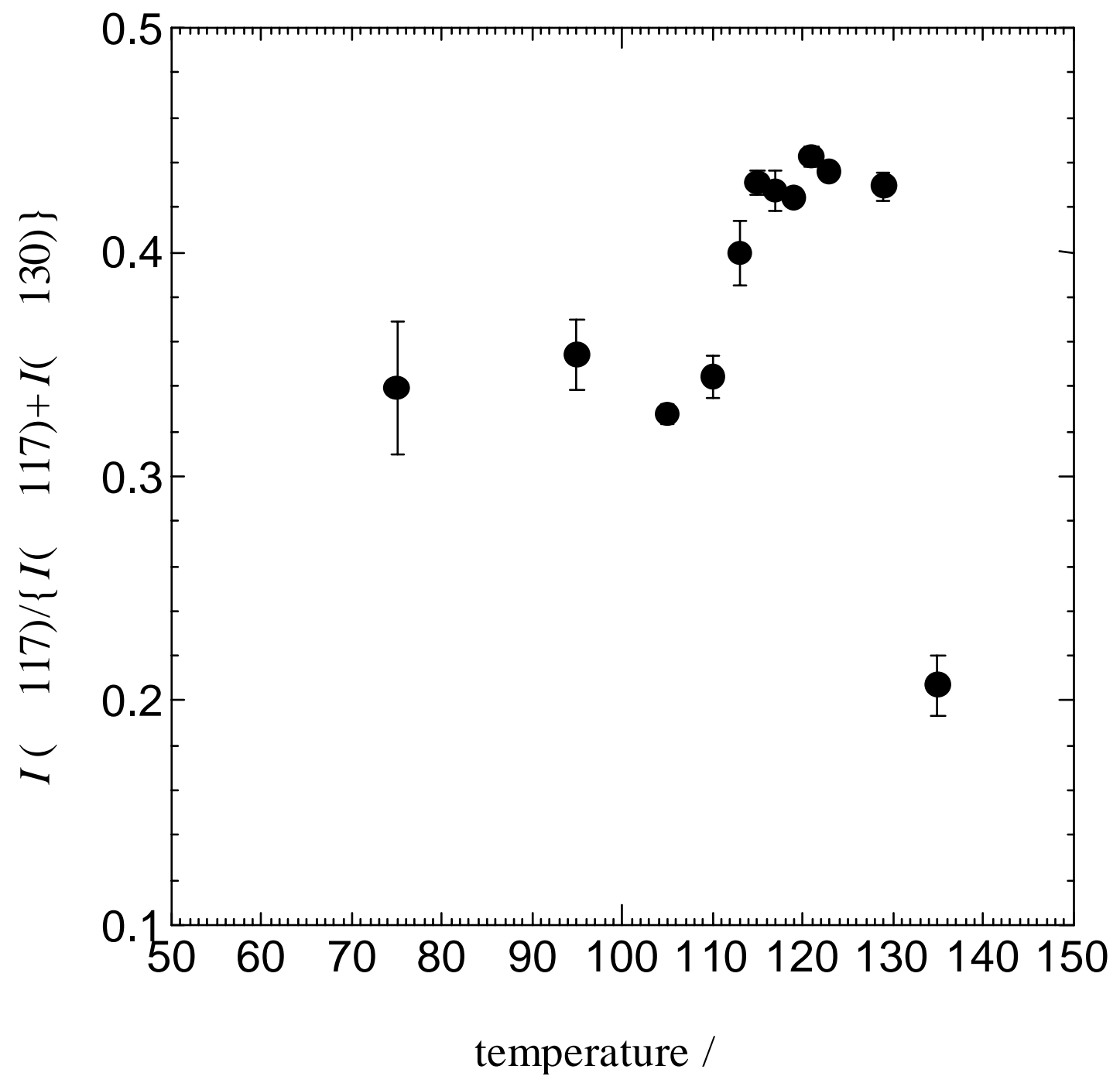

Figure 4 Koji Nozaki, et al. 




Figure 5 Koji Nozaki, et al. 


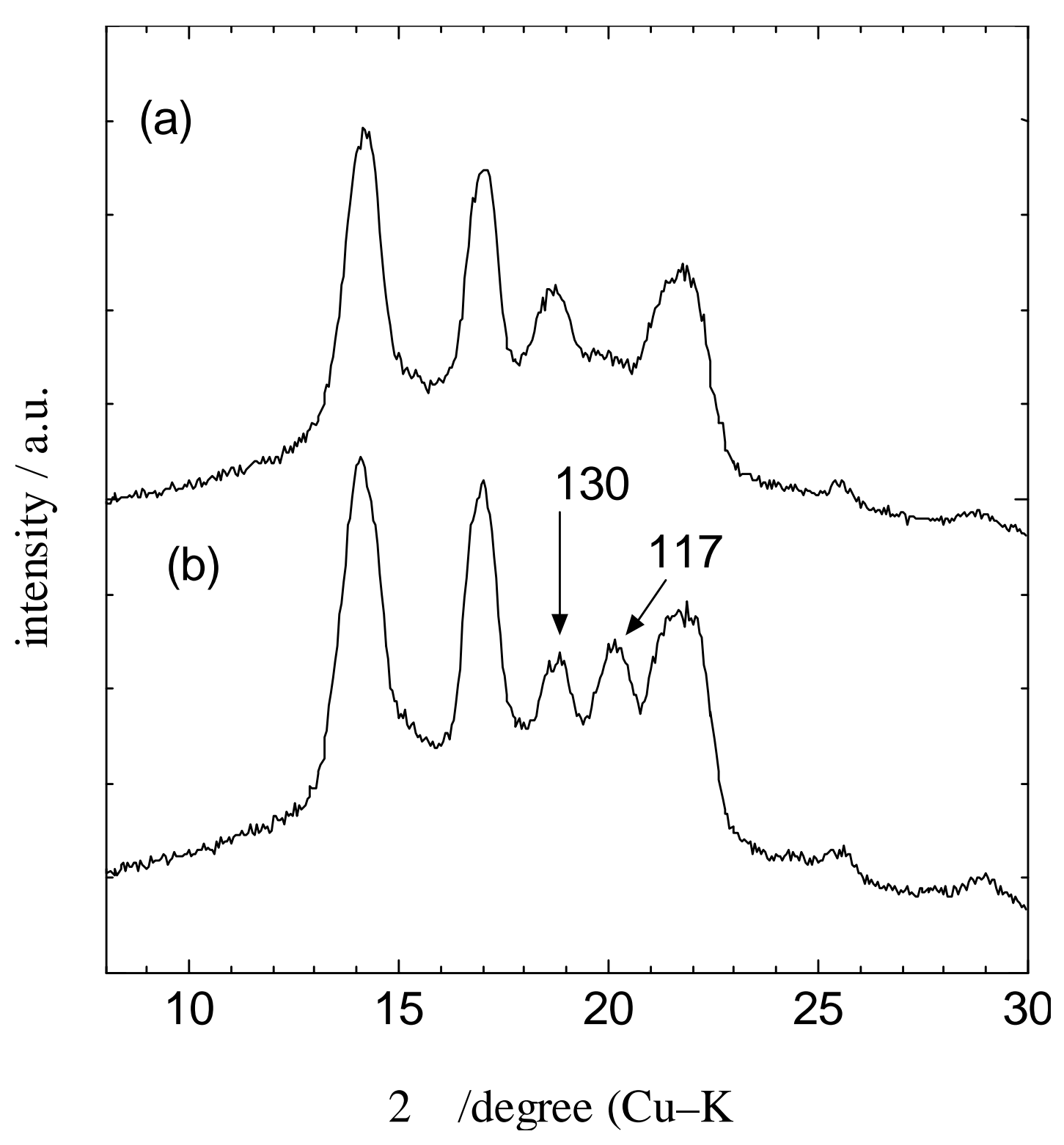

Figure 6 Koji Nozaki, et al. 